\title{
FDG-PET Findings of Intraductal Oncocytic Papillary Neoplasms of the Pancreas: Two Case Reports
}

\author{
Takashi Kato $^{a}$ Shuji Ikari $^{a}$ Kenji Hirata $^{d}$ \\ Takuro Machida $^{a}$ Hideaki Nakamura $^{a}$ Takashi Meguro $^{a}$ \\ Takayuki Morita $^{b}$ Toshiyuki Takahashi $^{c} \quad$ Nagara Tamaki $^{d}$ \\ Shoichi Horita ${ }^{a}$ \\ Departments of ${ }^{\mathrm{a}}$ Internal Medicine, ${ }^{\mathrm{b}}$ Surgery and ${ }^{\mathrm{C}}$ Pathology, Hokkaido \\ Gastroenterology Hospital, and ${ }^{\mathrm{d}}$ Department of Nuclear Medicine, Hokkaido \\ University Graduate School of Medicine, Sapporo, Japan
}

\section{Key Words}

Intraductal oncocytic papillary neoplasm · FDG-PET · Intraductal papillary mucinous neoplasm

\begin{abstract}
Intraductal oncocytic papillary neoplasm (IOPN) of the pancreas is a rare pancreatic tumor. To date, there have been three case reports of IOPN which showed strong positivity on 18F-fluorodeoxyglucose positron emission tomography (FDG-PET), raising the possibility of distinguishing IOPNs from other intraductal papillary mucinous neoplasms (IPMNs) using FDG-PET. However, all three cases had large tumors, approximately $10 \mathrm{~cm}$ in diameter, and there are no case reports of FDG-PET findings of small IOPNs, i.e. tumors the average size of malignant IPMNs $(3-5 \mathrm{~cm})$. We report two cases with IOPN of average size with FDG-PET findings. Computed tomography (CT) showed a multilocular cystic lesion $4 \mathrm{~cm}$ in diameter with a mural nodule $1 \mathrm{~cm}$ in diameter (case 1) and a cystic lesion $5 \mathrm{~cm}$ in diameter with a papillary mural nodule $4 \mathrm{~cm}$ in diameter (case 2). FDG-PET showed abnormal uptake at the same location as the pancreatic tumor revealed by $\mathrm{CT}$ in both cases. The maximum standardized uptake values of the lesions were 3.4 and 4.2, respectively. Surgical resection was performed and the tumor was diagnosed as IOPN with carcinoma in situ (case 1) and IOPN with minimal invasion (case 2). FDG-PET may be useful for diagnosing malignancy in IOPN, as it is in IPMN. However, in our two cases, strong accumulation was not observed in the IOPNs, which were within the average size range of malignant IPMNs.
\end{abstract}




\section{Introduction}

Intraductal oncocytic papillary neoplasm (IOPN) of the pancreas is a rare pancreatic tumor, first described by Adsay et al. in 1996 [1]. In the 2010 WHO classification of tumors of the pancreas, IOPNs are classified histopathologically among the subtypes of intraductal papillary mucinous neoplasms (IPMNs) as 'oncocytic-type IPMNs' on the basis of the predominant architectural and cell differentiation pattern [2]. IOPNs are characterized as intraductal neoplasms consisting of cells with abundant, intensely eosinophilic (oncocytic) cytoplasm showing complex thick papillae with intraepithelial lumina and severe/high-grade atypia corresponding to carcinoma in situ (CIS) [2]. Although it is difficult to distinguish IOPNs from other IPMNs employing clinical imaging examinations, IOPNs reportedly showed high 18F-fluorodeoxyglucose (FDG) uptake as compared with other IPMNs because oncocytic cells are highly active metabolically [3]. We report two IOPN cases with a brief review of the literature on FDG positron emission tomography (FDG-PET) findings of IOPN.

\section{Case 1}

A 43-year-old man presented to our hospital because of an abnormality detected on screening abdominal ultrasound examination in October 2009. He had neither clinical complaints nor any relevant previous history. Contrast-enhanced computed tomography (CT) showed a multilocular cystic lesion $4 \mathrm{~cm}$ in diameter with calcification in the head of the pancreas. The cystic lesion of the pancreas contained a slightly enhanced mural nodule $1 \mathrm{~cm}$ in diameter (fig. 1a). The patient was admitted to our hospital for further examination of the pancreatic lesion. Laboratory data on admission including tumor markers were within normal limits. Endoscopic ultrasonography showed a mural nodule $1 \mathrm{~cm}$ in diameter in the lesion, consistent with the CT findings. Magnetic resonance cholangiopancreatography (MRCP) demonstrated a multicystic lesion at the pancreatic head without dilatation of the main pancreatic duct or the common bile duct (fig. 1b). FDG-PET showed abnormal uptake in the upper abdomen at the same location as the mural nodule revealed by CT (fig. 1c). The maximum standardized uptake value (SUV $\max$ ) of the lesion was 3.4. On the basis of these findings, IPMN with a mural nodule $1 \mathrm{~cm}$ in diameter was diagnosed and substomach-preserving pancreatoduodenectomy was performed because of the mural nodule, which showed FDG uptake, and the size of the lesion.

The surgically resected specimen showed a multicystic lesion $4 \mathrm{~cm}$ diameter in the pancreatic head. Communication between the ductal system and the cystic lesion was confirmed by injection of contrast medium into a section of the main pancreatic duct. On the cut surface, the cysts were filled with achromatic, transparent mucus. Microscopically, a papillary mural nodule measuring $1.3 \times 0.7 \mathrm{~cm}$ was recognized in one cyst near the duodenum by low-power magnification (ig. $2 \mathrm{a}$ ). Neoplastic epithelium showed arboriform or papillary growth on the narrow stalk with polarity disorder of the nuclei. The tumor cells had oncocytic cytoplasm including abundant eosinophilic granules and oval nuclei with increased chromatin and a large nucleolus by high-power magnification (fig. 2b). Phosphotungstic acid-hematoxylin (PTAH) stain resulted in dense blue cytoplasmic granularity (fig. 2c). Invasive growth was not seen. On the basis of these findings, the lesion was diagnosed as IOPN with CIS. Since the site of calcification was apparently apart from the nodule, no causal relationship between calcification and the tumor was discernible.

The patient had an uneventful postoperative course and was discharged from the hospital on the 59 th postoperative day. He remains well, with no evidence of recurrent disease, 18 months after the operation. 


\section{Case 2}

A 72-year-old man was referred to our hospital for a pancreatic tumor detected on abdominal ultrasound in December 2011. He had undergone abdominal surgery for early gastric cancer 33 years previously. Blood tests showed mild anemia (hemoglobin $10.9 \mathrm{~g} / \mathrm{dl}$; normal reference 13.5-17.6 g/dl), low total protein $(4.8 \mathrm{~g} / \mathrm{dl}$; normal reference $6.5-8.3 \mathrm{~g} / \mathrm{dl})$, mildly elevated lactate dehydrogenase (294 IU/l; normal reference 120-245 IU/l) and HbA1c (7.0\%; normal reference 4.3-5.8\%). Fasting blood sugar and tumor markers, e.g. CEA and CA19-9, were within normal ranges (fasting blood sugar $99 \mathrm{mg} / \mathrm{dl}$, CEA $3.9 \mathrm{ng} / \mathrm{ml}$, CA19-9 $35 \mathrm{U} / \mathrm{ml}$ ). Contrast-enhanced CT showed a cystic lesion $5 \mathrm{~cm}$ in diameter in the head of the pancreas. This cystic lesion contained a slightly enhanced papillary mural nodule $4 \mathrm{~cm}$ in diameter (fig. 3a). MRCP demonstrated a cystic lesion at the pancreatic head with dilatation of the main pancreatic duct (fig. 3b). FDG-PET was performed after a 6-hour fast and glucose was $129 \mathrm{mg} / \mathrm{dl}$ before FDG administration. FDG-PET showed abnormal uptake in the upper abdomen at the same location as the pancreatic tumor revealed by CT (fig. 3c). The SUV $\max$ of the lesion was 4.2 (fig. 3c). Endoscopic retrograde pancreatography revealed marked cystic dilatation of the main pancreatic duct in the head and diffuse dilatation of other parts of the main pancreatic duct. Luminal filling defects due to the polypoid mural tumor or amorphous mucin were observed in the cystic lesion. IOPN was suggested from brushing cytology of the main pancreatic duct in the pancreatic head. On the basis of these findings, IOPN with a mural nodule $4 \mathrm{~cm}$ in diameter was diagnosed and pancreatoduodenectomy was performed.

The surgically resected specimen was a cystic lesion $5 \mathrm{~cm}$ in diameter in the pancreatic head (fig, 4a). Injection of contrast medium into a section of the main pancreatic duct revealed a localized cystic dilatation of the pancreatic duct with luminal filling defects (fig. 4a). Microscopically, a papillary mural nodule measuring $4.5 \times 2.2 \mathrm{~cm}$ was recognized in the cystic dilated pancreatic duct with a thickened and fibrous wall. The origin of the dilated pancreatic duct, which was main pancreatic duct or a branch duct, could not be identified pathologically. Minimally invasive growth was seen without invasion of lymph or blood vessels (fig. 4b). Neoplastic epithelia showed specific findings of the oncocytic type of IPMN, as in case 1 (fig. 4c). No lymph node metastasis was found. On the basis of these findings, the lesion was diagnosed as IOPN with minimal invasion.

The patient had an uneventful postoperative course and was discharged from the hospital on the 23rd postoperative day.

\section{Discussion}

FDG-PET plays an expanding role in diagnosing several tumors including pancreatic cancers, as well as in identifying distant metastasis and recurrence. Moreover, it has been suggested that FDG-PET would be useful for differentiating pancreatic cancer from tumor-forming pancreatitis [4]. Although the experience with FDG-PET in the evaluation of IPMNs is presently limited, recent studies have suggested that FDG-PET is more accurate than conventional imaging modalities in distinguishing benign from malignant lesions. Sperti et al. [5] reported that FDG-PET had sensitivity, specificity, positive and negative predictive values and accuracy in detecting malignant IPMNs of 92, 97, 96, 95 and 95\%, respectively, as compared to CT and/or magnetic resonance values of only $58,82,68,74$ and $72 \%$, respectively, based on a prospective evaluation of 64 patients with suspected IPMNs. In this study, focal uptake with a SUV $\geq 2.5$ was considered positive for malignancy. Hong et al. [6] also demonstrated that FDG-PET/CT outperformed multidetector CT in detecting malignant IPMNs in a retrospective analysis of 31 patients with pancreatic IPMN. Moreover, other studies found FDG-PET to have additional value in the diagnosis of malignant IPMN. Tomimaru et al. [7] reported that the combination of a mural nodule detected on CT and a SUV $\max$ of 2.5 obtained by FDG-PET offered the best diagnosis of malignant IPMN in a prospective investigation of 29 patients with histopathologically proven IPMN. Takanami et al. [8] 
reported that FDG-PET/CT showed excellent diagnostic accuracy for differentiating between benign and malignant IPMNs with mural nodules on contrast-enhanced CT in a retrospective study of 16 patients with surgically proven IPMN. In our present cases, FDG-PET findings were useful as well for treatment determination because it was possible to confirm malignancy from the SUV (case 1: 3.4; case 2: 4.2). However, subtypes of IPMN were not discussed in earlier studies and little is known about differences in FDG-PET findings among subtypes of IPMNs.

Although IOPN has obvious malignant potential and preoperative diagnosis is important, clinical imaging features of IOPN are similar to those of other types of IPMN, and it is thus difficult to make a preoperative diagnosis of IOPN [9]. FDG-PET findings of IOPN reportedly differed from those of IPMN [3]. However, to the best of our knowledge, there have been only three case reports of FDG-PET findings of IOPN $[3,9,10]$. Table 1 summarizes the IOPN cases in whom FDG-PET was performed. Noji et al. [3] reported the first case of IOPN showing strong accumulation of FDG in the tumor and suggested that IOPN may be differentiated from other IPMNs by FDG-PET based on the high metabolic activity of IOPN. As in the first case, high SUVs in the mural nodule within the cystic components were present in the other two cases. Thus, Kato et al. [9] and Fischer et al. [10] also described FDG-PET as being a potentially useful modality for distinguishing IOPN from other pancreatic cystic tumors. However, these three cases had extremely large tumors, approximately $10 \mathrm{~cm}$ in maximum diameter, with solid components. The mean lesion size was $6.4 \mathrm{~cm}$ (range $1.5-15 \mathrm{~cm}$ ) in 20 patients with IOPN reported in the English and Japanese literature through 2008 [9]. To confirm that IOPN has higher FDG uptake than other types of malignant IPMN, examination of FDG-PET findings of IOPN comparable in size to the average malignant IPMN is necessary. The reported average size of malignant IPMNs was $3.4 \pm 1.8 \mathrm{~cm}$ in 445 surgical cases [11]. The tumors in our cases were within the average size range of malignant IPMN. The average SUV of malignant IPMNs was reported to be $6.7 \pm 3.6$ (1 CIS and 14 invasive carcinomas) [6], $4.7 \pm 3.0$ (3 CIS and 11 invasive carcinomas) [7] or $2.7 \pm 0.6$ (8 CIS and 1 invasive carcinoma) [8]. The $\mathrm{SUV}_{\max }$ of our cases were 3.4 (case 1) and 4.2 (case 2), not significantly different from that of malignant IPMN. Although more IOPN cases must be accumulated, the differentiation of IOPN from other malignant IPMNs by FDG-PET may be difficult in tumors of average size.

In conclusion, FDG-PET may be useful for diagnosing whether IOPN is a malignant tumor, as it is for IPMN. In IOPN of average size, differentiation between IOPN and malignant IPMN appears to be difficult, because the SUV $V_{\max }$ in our cases did not show a 'strong' value and were similar to those of previously reported malignant IPMNs. 
Table 1. Summary of IOPN cases with FDG-PET findings

\begin{tabular}{|c|c|c|c|c|c|c|c|c|c|}
\hline Case & Reference & Age & Sex & Location & Size, $\mathrm{cm}$ & Mural nodule & Pathology & FDG-PET & SUV \\
\hline 1 & $\begin{array}{l}\text { Noji et al., } \\
2002 \text { [3] }\end{array}$ & 68 & $\mathrm{~F}$ & head & $12.0 \times 6.5 \times 4.9$ & $\begin{array}{l}\text { largest nodule } \\
3.0 \mathrm{~cm} \text { in } \\
\text { diameter }\end{array}$ & non-invasive & $\begin{array}{l}\text { intense focal uptake } \\
\text { seen in the solid area } \\
\text { of the tumor }\end{array}$ & 8.5 \\
\hline 2 & $\begin{array}{l}\text { Kato et al., } \\
2008 \text { [9] }\end{array}$ & 69 & $\mathrm{~F}$ & head & $9.1 \times 7.5 \times 4.5$ & $\begin{array}{l}\text { papillary } \\
\text { mural nodules } \\
\text { of various size }\end{array}$ & non-invasive & $\begin{array}{l}\text { very strong uptake } \\
\text { seen in the thick wall } \\
\text { and mural nodule }\end{array}$ & 14.6 \\
\hline 3 & $\begin{array}{l}\text { Fischer et al., } \\
2010 \text { [10] }\end{array}$ & 76 & $\mathrm{~F}$ & $\begin{array}{l}\text { head } \\
\text { and tail }\end{array}$ & 10.0 & $\begin{array}{l}\text { a } 6.0 \mathrm{~cm} \text { solid } \\
\text { area }\end{array}$ & $\begin{array}{l}\text { invasive with } \\
\text { lymph node } \\
\text { metastasis }\end{array}$ & $\begin{array}{l}\text { increased uptake } \\
\text { seen in the intracystic } \\
\text { solid tumor parts }\end{array}$ & 17.8 \\
\hline 4 & $\begin{array}{l}\text { this report, } \\
\text { case } 1\end{array}$ & 43 & M & head & 4.0 & $\begin{array}{l}\text { papillary } \\
\text { mural nodule } \\
\text { measuring } \\
1.3 \times 0.7 \mathrm{~cm}\end{array}$ & non-invasive & $\begin{array}{l}\text { abnormal uptake } \\
\text { seen in the mural } \\
\text { nodule }\end{array}$ & 3.4 \\
\hline 5 & $\begin{array}{l}\text { this report, } \\
\text { case } 2\end{array}$ & 72 & M & head & 5.0 & $\begin{array}{l}\text { papillary } \\
\text { mural nodule } \\
\text { measuring } \\
4.5 \times 2.2 \mathrm{~cm}\end{array}$ & $\begin{array}{l}\text { minimally } \\
\text { invasive }\end{array}$ & $\begin{array}{l}\text { abnormal uptake } \\
\text { seen in the pancreatic } \\
\text { tumor }\end{array}$ & 4.2 \\
\hline
\end{tabular}



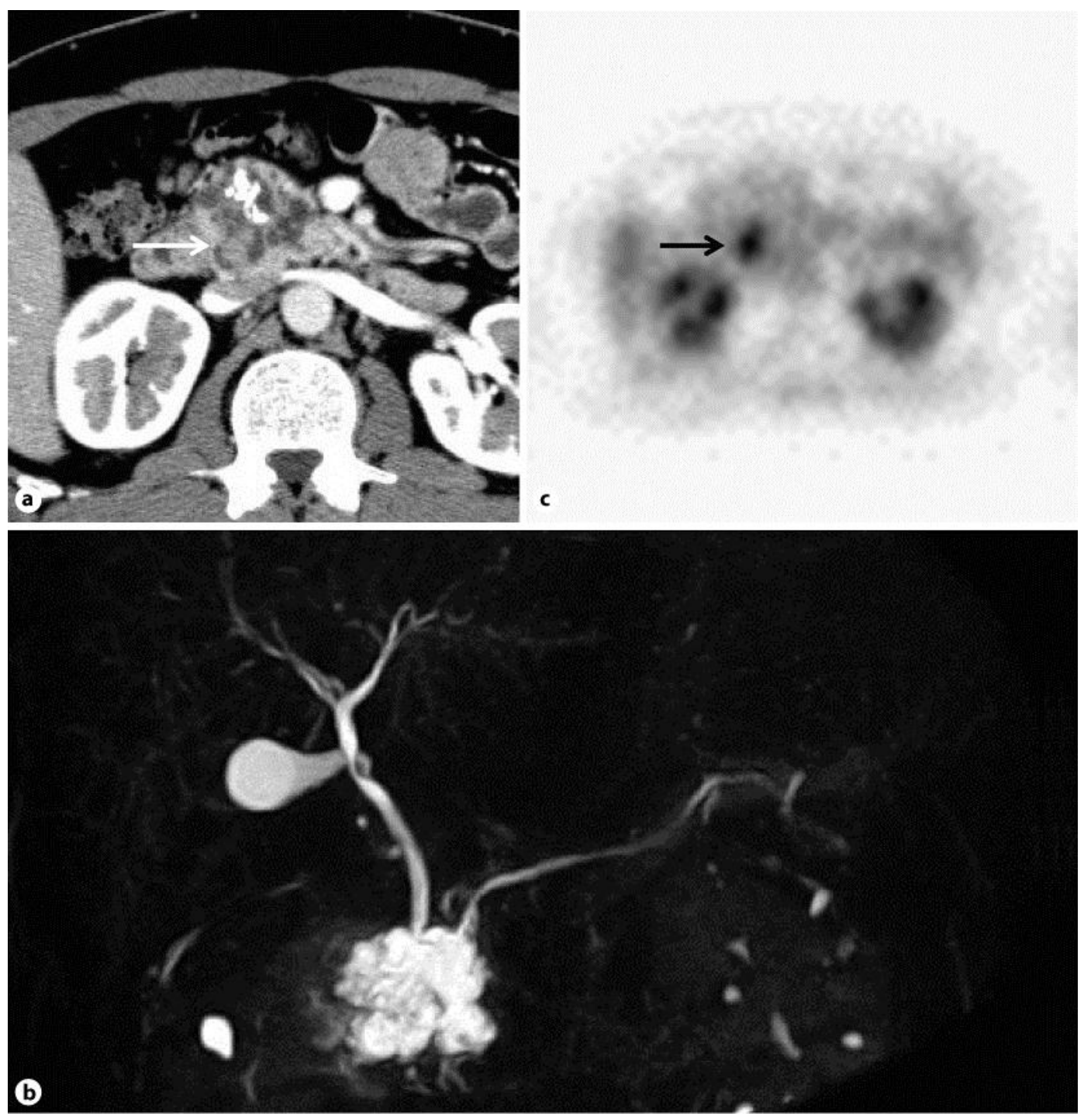

Fig. 1. a Contrast-enhanced CT showed a multilocular cystic lesion $4 \mathrm{~cm}$ in diameter with calcification in the head of the pancreas. The cystic lesion contained a slightly enhanced mural nodule $1 \mathrm{~cm}$ in diameter (arrow). b MRCP demonstrated a multicystic lesion at the pancreatic head without dilatation of the main pancreatic duct or the common bile duct. c An axial FDG-PET image showed abnormal uptake in the upper abdomen at the same location as the mural nodule on CT (arrow). The SUV max was 3.4 . 


\begin{tabular}{r|l|l|l}
$\begin{array}{r}\text { Case Reports in } \\
\text { Gastroenterology }\end{array}$ & $\begin{array}{l}\text { Case Rep Gastroenterol 2012;6:415-424 } \\
\text { DOI: 10.1159/000339916 }\end{array}$ & $\begin{array}{l}\text { Published online: } \\
\text { June 26, 2012 }\end{array}$ & $\begin{array}{l}\text { @ 2012 S. Karger AG, Basel } \\
\text { ISSN 1662-0631 } \\
\text { www.karger.com/crg }\end{array}$ \\
\hline
\end{tabular}

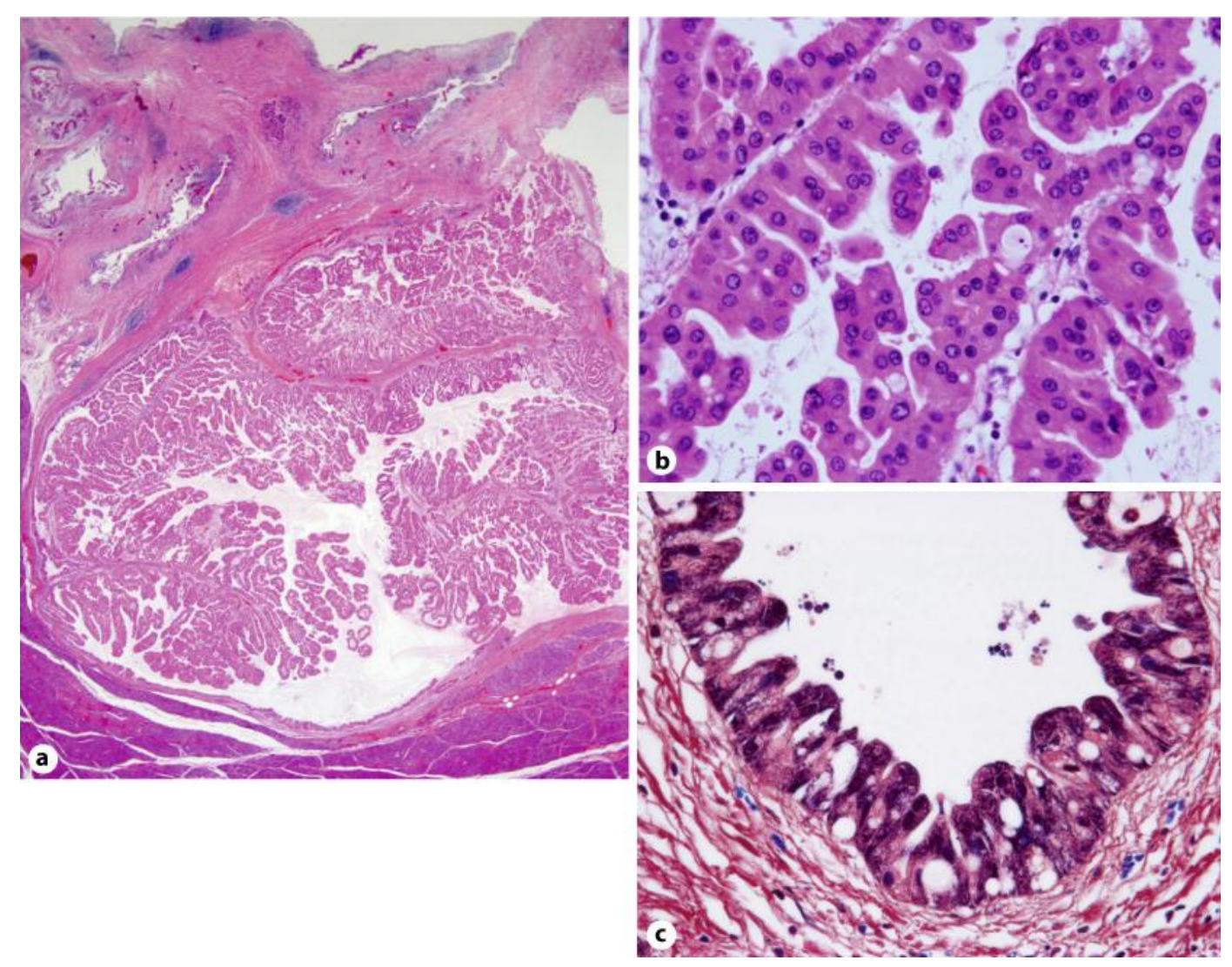

Fig. 2. a The cysts were filled with achromatic, transparent mucus. A papillary mural nodule was recognized in one cyst near the duodenum (HE stain, $\times 100$ ). $\mathbf{b}$ The tumor cells had oncocytic cytoplasm including abundant eosinophilic granules and oval nuclei with increased chromatin and a large nucleolus by high-power magnification (HE stain, $\times 400$ ). c PTAH stain resulted in dense blue cytoplasmic granularity $(\times 400)$. 


\begin{tabular}{r|l|l|l}
$\begin{array}{r}\text { Case Reports in } \\
\text { Gastroenterology }\end{array}$ & $\begin{array}{l}\text { Case Rep Gastroenterol 2012;6:415-424 } \\
\text { DOI: 10.1159/000339916 }\end{array}$ & $\begin{array}{l}\text { Published online: } \\
\text { June 26, 2012 }\end{array}$ & $\begin{array}{l}\text { @ 2012 S. Karger AG, Basel } \\
\text { ISSN 1662-0631 } \\
\text { www.karger.com/crg }\end{array}$ \\
\hline
\end{tabular}
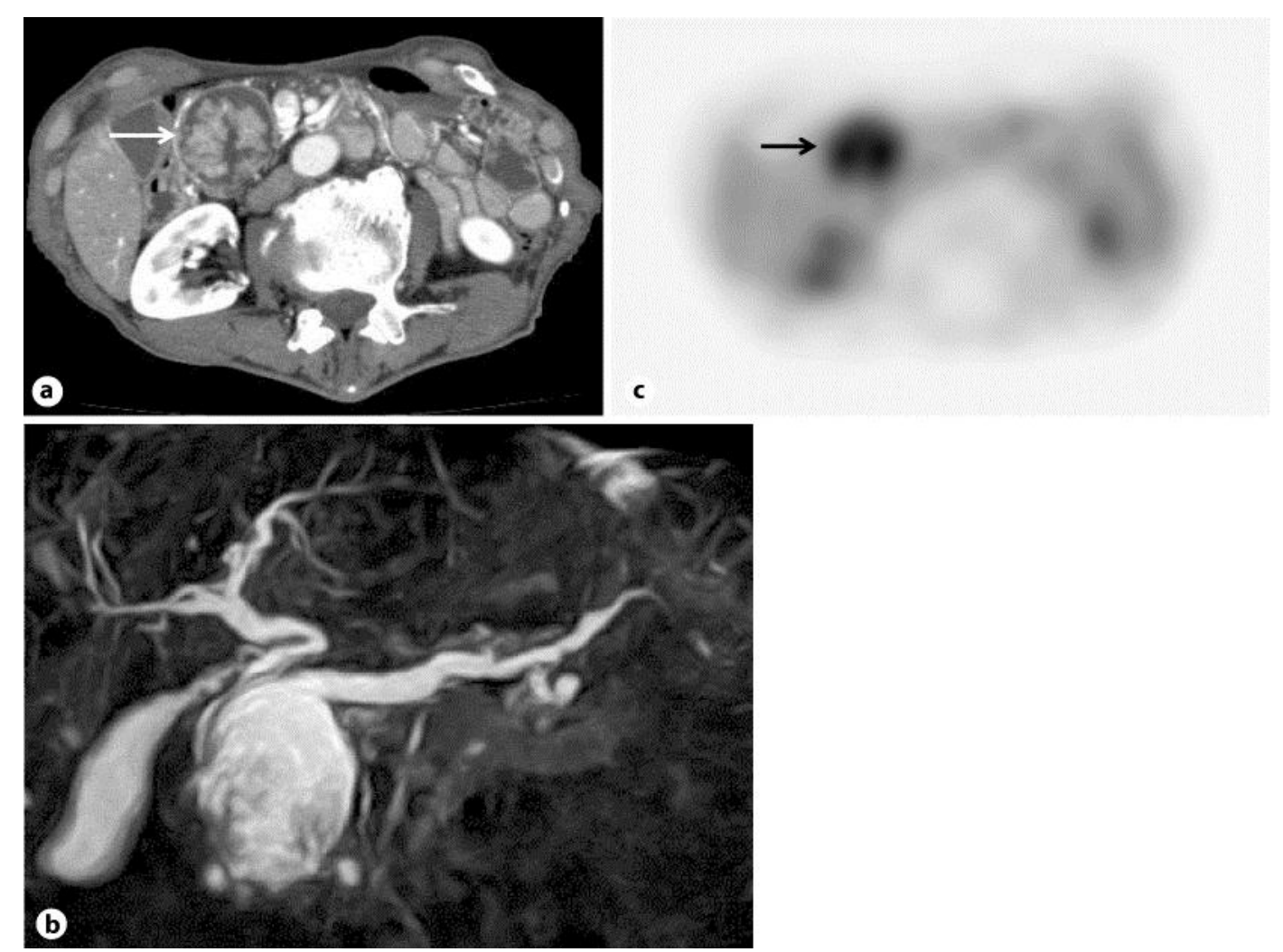

Fig. 3. a Contrast-enhanced CT showed a cystic lesion $5 \mathrm{~cm}$ in diameter which contained a slightly enhanced papillary mural nodule $4 \mathrm{~cm}$ in diameter in the head of the pancreas (arrow). $\mathbf{b}$ MRCP demonstrated a cystic lesion at the pancreatic head with dilatation of the main pancreatic duct. c An axial FDG-PET image showed abnormal uptake in the upper abdomen at the same location as the pancreatic tumor on CT (arrow). The SUV $\max$ was 4.2 . 


\begin{tabular}{r|l|l|l} 
Case Reports in & $\begin{array}{l}\text { Case Rep Gastroenterol 2012;6:415-424 } \\
\text { DOI: 10.1159/000339916 }\end{array}$ & $\begin{array}{l}\text { Published online: } \\
\text { June 26, 2012 }\end{array}$ & $\begin{array}{l}\text { @ 2012 S. Karger AG, Basel } \\
\text { ISSN 1662-0631 } \\
\text { www.karger.com/crg }\end{array}$ \\
\hline
\end{tabular}
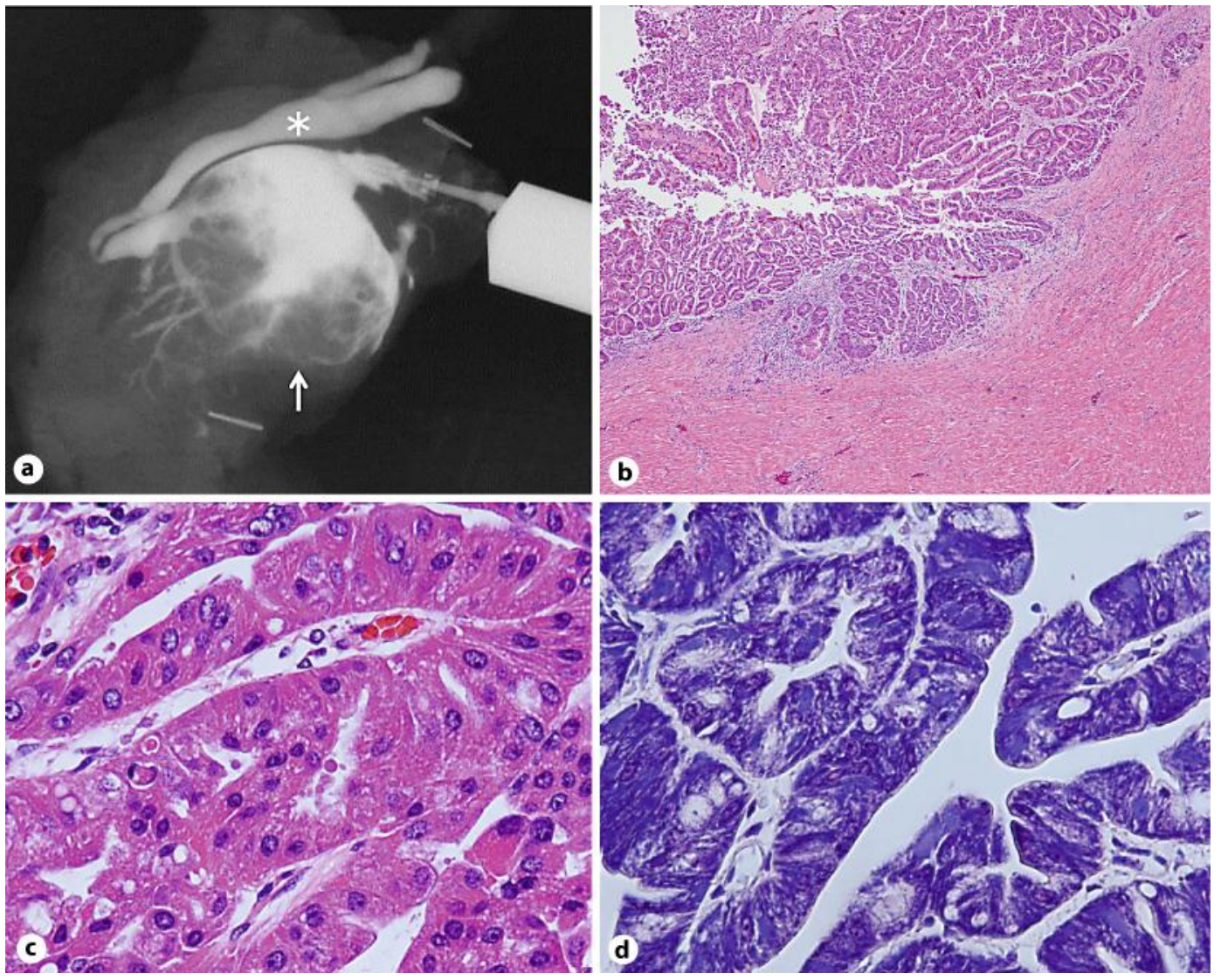

Fig. 4. a Postoperative contrast radiography of the main pancreatic duct in the resected specimen showed a localized cystic dilatation of the main pancreatic duct with luminal filling defects (arrow). The common bile duct was observed above the cystic lesion (asterisk). $\mathbf{b}$ A papillary mural nodule was recognized in the cyst with minimally invasive growth (HE stain, $\times 40$ ). $\mathrm{c}$ The tumor cells had oncocytic cytoplasm including abundant eosinophilic granules and oval nuclei with increased chromatin and a large nucleolus by high-power magnification (HE stain, $\times 400$ ). $d$ PTAH stain resulted in dense blue cytoplasmic granularity $(\times 200)$.

\section{References}

1 Adsay NV, Adair CF, Heffess CS, Klimstra DS: Intraductal oncocytic papillary neoplasms of the pancreas. Am J Surg Pathol 1996;20:980-994.

2 Adsay NV, Fukushima N, Furukawa T, Hruban RH, Klimstra DS: Intraductal neoplasms of the pancreas; in Bosman FT, Carneiro F, Hruban RH, Theise ND (eds): WHO Classification of Tumours of the Digestive System. Lyon, IARC Press, 2010, pp 304-313.

-3 Noji T, Kondo S, Hirano S, et al: Intraductal oncocytic papillary neoplasm of the pancreas shows strong positivity on FDG-PET. Int J Gastrointest Cancer 2002;32:43-46.

4 Nakamoto Y, Higashi T, Sakahara H, et al: Delayed (18)F-fluoro-2-deoxy-D-glucose positron emission tomography scan for differentiation between malignant and benign lesions in the pancreas. Cancer 2000;89:2547-2554.

5 Sperti C, Bissoli S, Pasquali C, et al: 18-Fluorodeoxyglucose positron emission tomography enhances computed tomography diagnosis of malignant intraductal papillary mucinous neoplasms of the pancreas. Ann Surg 2007;246:932-939.

6 Hong HS, Yun M, Cho A, et al: The utility of F-18 FDG PET/CT in the evaluation of pancreatic intraductal papillary mucinous neoplasm. Clin Nucl Med 2010;35:776-779. 
7 Tomimaru Y, Takeda Y, Tatsumi M, et al: Utility of 2-[18F] fluoro-2-deoxy-D-glucose positron emission tomography in differential diagnosis of benign and malignant intraductal papillary-mucinous neoplasm of the pancreas. Oncol Rep 2010;24:613-620.

-8 Takanami K, Hiraide T, Tsuda M, et al: Additional value of FDG PET/CT to contrast-enhanced CT in the differentiation between benign and malignant intraductal papillary mucinous neoplasms of the pancreas with mural nodules. Ann Nucl Med 2011;25:501-510.

-9 Kato Y, Nakagouri T, Konishi M, et al: Intraductal oncocytic papillary neoplasm of the pancreas with strong accumulation on FDG-PET. Hepatogastroenterology 2008;55:900-902.

10 Fischer MA, Donati O, Heinrich S, et al: Intraductal oncocytic papillary neoplasm of the pancreas: a radio-pathological case study. JOP 2010;11:49-54.

-11 Suzuki Y, Atomi Y, Sugiyama M, et al: Cystic neoplasm of the pancreas: a Japanese multiinstitutional study of intraductal papillary mucinous tumor and mucinous cystic tumor. Pancreas 2004;28:241-246. 